\title{
Antimicrobial Effect of Leukocyte- and Platelet-Rich Fibrin Against Aggregatibacter actinomycetemcomitans Mono-Multiserotypes Model
}

\author{
Efecto Antimicrobiano de la Fibrina Rica en Plaquetas y Leucocitos Contra \\ Aggregatibacter actinomycetemcomitans en un Modelo Mono-Multi Serotipos
}

\author{
Nicole Lanata-Selingue'; Daniel Betancur'; Helia Bello-Toledo ${ }^{2,3}$; \\ Gerardo González-Rocha ${ }^{2,3}$; Luis Luengo ${ }^{4}$ \& Gabriela Sánchez-Sanhueza ${ }^{2,3,5}$
}

LANATA-SELINGUE, N.; BETANCUR, D.; BELLO-TOLEDO, H.; GONZÁLEZ-ROCHA, G.; LUENGO, L. \& SÁNCHEZSANHUEZA, G. Antimicrobial effect of leukocyte- and platelet-rich fibrin against an Aggregatibacter actinomycetemcomitans mono-multiserotype model. Int. J. Odontostomat., 15(4):1035-1042, 2021.

\begin{abstract}
Leukocyte- and platelet-rich fibrin is a widely used platelet concentrate for periodontal surgery procedures. Many benefits are described regarding its use, such as antimicrobial properties. The objective of this study was to evaluate the antimicrobial effects of the different zones of this platelet concentrated against the most prevalent serotypes of Aggregatibacter actinomycetemcomitans in an in vitro mono-multiserotype model. Three patients who were treated at a School of Dentistry in the city where the researchers reside, were included. Modified direct contact method tests and results were analyzed using multivariate logistic regression analysis. In the modified direct contact method test, a decrease in bacterial count was found at time 1 , but at time 2 , the count increased for all serotypes and zones of L-PRF. It can be noted that the areas with more cellular content in leukocytes and platelet-rich fibrin are the areas with the most antimicrobial power. This platelet concentrate would have better results with serotype $\mathrm{c}$. At time point 2 , it is likely to act as a growth promoter of A. actinomycetemcomitans.
\end{abstract}

KEY WORDS: Aggregatibacter actinomycetemcomitans, dental implants, infections, platelet-rich fibrin

\section{INTRODUCTION}

Platelet concentrates are autologous products obtained from centrifugation of a patient's own blood (Dohan Ehrenfest et al., 2009). In this procedure, the active components of the blood are collected and prepared in a way that is clinically usable, for example, in the form of a solution or gel that can be placed on a surgical site for tissue regeneration purposes (Bielecki et al., 2012; Bielecki \& Dohan Ehrenfest, 2012a). Platelet concentrates are classified into P-PRP (pure platelet-rich plasma), L-PRP (leukocytes and plateletrich plasma), P-PRF (pure platelet-rich fibrin), and LPRF (leukocytes and platelet-rich fibrin) (Dohan Ehrenfest et al., 2010).
L-PRF has several advantages: it is an inexpensive, simple, and an atraumatic technique (Anwandter et al., 2016) that does not use anticoagulants. Its polymerization is slow and natural, and the fibrin network has a three-dimensional configuration, which allows the retention of cytokines for longer periods of time (7-11 days) and in the form of a membrane with great elasticity and flexibility (Kumar \& Shubhashini, 2013; Khiste \& Naik Tari, 2013).

L-PRF is attributed to properties that favor the surgical site, such as modulating the inflammatory response, increasing the effectiveness of regeneration,

${ }^{1}$ Oral Surgical Stomatology Department, School of Dentistry, Universidad de Concepción, Concepción, Chile.

${ }^{2}$ Department of Microbiology, Faculty of Biological Sciences, Research Laboratory on Antibacterial Agents, Universidad de Concepción, Concepción, Chile.

${ }^{3}$ Millennium Nucleus on Interdisciplinary Approach to Antimicrobial Resistance, Chile (MICROB-R).

${ }^{4}$ Department of Public Health and Preventive dentistry, School of Dentistry, Universidad de Concepción,Concepción, Chile.

${ }^{5}$ Restorative Department, School of Dentistry, Universidad de Concepción, Concepción, Chile. 
LANATA-SELINGUE, N.; BETANCUR, D.; BELLO-TOLEDO, H.; GONZÁLEZ-ROCHA, G.; LUENGO, L. \& SÁNCHEZ-SANHUEZA, G. Antimicrobial effect of leukocyte- and platelet-rich fibrin against an Aggregatibacter actinomycetemcomitans mono-multiserotype model. Int. J. Odontostomat., 15(4):1035-1042, 2021.

angiogenesis, and neovascularization, and decreasing pain and edema postoperatively (Choukroun et al., 2006).

Several studies have analyzed L-PRF by zone, according to its cell concentration (Kobayashi et al., 2012; Bootkrajang et al., 2020; Dias et al., 2020). Different nomenclatures have been used to identify these zones. This study used the nomenclature proposed by Dohan Ehrenfest et al. (2018), where the head, body, and tail are used for classification of the different zones. The head is the closest to the red zone, followed by the body, and then the tail.

Within the L-PRF zones, it has been noted that the density and organization of the fibrin network increase as they move away from the red zone. As they approach the red zone, there are more cells. Thus, the tail has higher fibrin organization and density, and the head has more cells (Kobayashi et al.; Bootkrajang et al.; Dias et al.).

Despite the noise caused by platelet concentrates in the overall dental community, there is little evidence of their antimicrobial effect (Moojen et al., 2008).

A common surgery in the dental community, implants, may have early or late infections (Aboltins et al., 2014). From sites where dental implants have failed, we most often find: Aggregatibacter actinomycetemcomitans, Porphyromonas gingivalis, Tannerella forsythia, Prevotella intermedia, Peptostreptococcus micros, Campylobacter rectus, Fusobacterium spp. and Capnocytophaga spp. among others (Quirynen et al., 2002).

A. actinomycetemcomitans is a Gram-negative, non-motile, facultative anaerobe coccobacilli and capnophilic bacteria (Slots \& Ting, 1999; Newman et al., 1976). This bacterium is part of the oral cavity microbiota in healthy individuals (Flores, 2011) and it has been found in $90 \%$ of patients with localized aggressive periodontitis and $30-50 \%$ of patients with severe chronic periodontitis (Raja et al., 2014). Infection by this bacterium leads to an inflammatory immune response, which causes an imbalance in the normal tissues of the periodontium, such as the gum, periodontal ligament, cement and alveolar bone, ultimately causing loss of the tooth piece (Herbert et al., 2016). This bacterium not only affects tooth pieces but can also colonize titanium surfaces, causing periimplant inflammation and bone loss(Nelson \& Thomas,
2010). There are seven serotypes of $A$. actinomycetemcomitans (Yang et al., 2005) but serotypes $\mathrm{a}, \mathrm{b}$, and $\mathrm{c}$ are the most frequently isolated from the oral cavity (De Bruyn et al., 2013).

It is important then to determine the antibacterial effect of L-PRF and its different zones, which could be used as a protocol for periodontal surgeries and dental implants, to reduce post-surgical infections. Thus, the objective of this study was to evaluate the antibacterial effect of the different areas of L-PRF against the most prevalent serotypes of $A$. actinomycetemcomitans in an in vitro monomultiserotype model.

\section{MATERIAL AND METHOD}

Design. This study used a randomized experimental research type. The investigation was carried out with ASA I patients ages 25-45 who were treated at the School of Dentistry in the city where the researchers reside. Patients who had smoked or used antibiotics in the three months prior to the evaluation were excluded from the study. Patients who were not willing or capable of providing written authorization were also excluded. The research work was reviewed by the bioethics committee of the Faculty of Dentistry in the city where the patients resided $\left(\mathrm{N}^{\circ} 30 / 19\right)$ and conducted in compliance with the conventions of the Declaration of Helsinki adopted by the World Medical Association.

Selection and sample size. Volunteers were recruited through convenience sampling. Potential participants were patients of students specializing in periodontics who had scheduled surgeries with the use of L-PRF. Usually, after surgery, some membranes are left over and are discarded. The intention was to use those excess membranes (if any) for the study. Each patient was asked for use of his or her leftover L-PRF membranes. Each participant provided informed consent. It should be noted that no extra punctures were performed, nor was additional blood taken for the study; only L-PRF membranes that were considered for surgery and were not necessary were utilized.

Protocol for obtaining L-PRF. Tubes (Vacuette $₫$, USA) of $9 \mathrm{~mL}$ were filled with a patient's blood and without anticoagulants, then centrifuged ( EBA-20, Hettich $\AA$, Canada). The centrifuge was calibrated to 2,700 revolutions in 12 minutes (Dohan Ehrenfest et 
al., 2006). The precise amount of blood depended upon what the provider deemed necessary for the patient's surgery.

When centrifugation was finished, the clot was separated from the red elements with an anatomical clamp and a modeling compound spatula, leaving all excess inside the tube. Clots were left in the PRF box to obtain membranes (Figs. 1 and 2) (Dohan Ehrenfest et al., 2010).

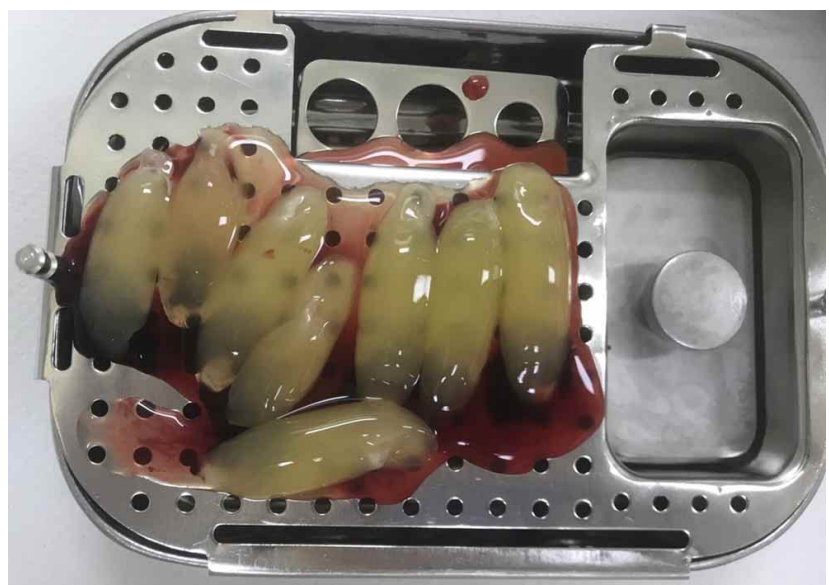

Fig. 1. Clots of L-PRF.

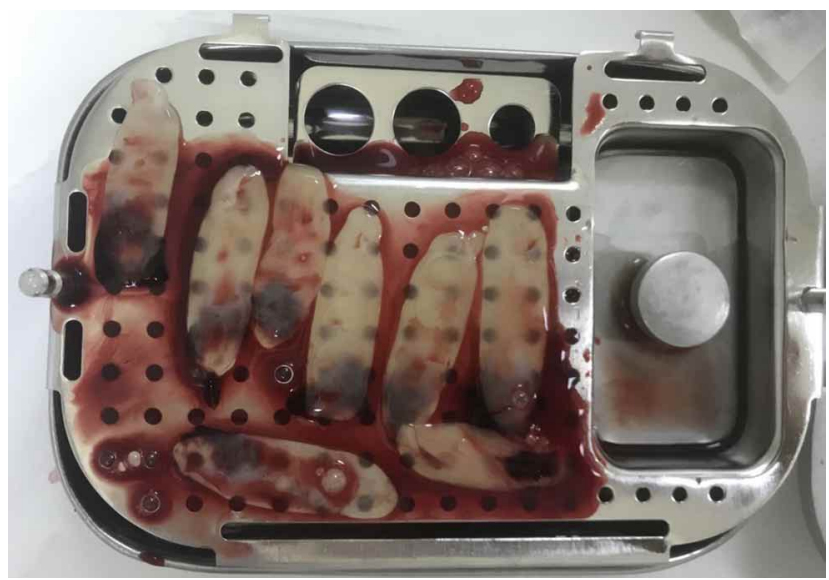

Fig. 2. L-PRF membranes.

Modified direct contact test. The strains of $A$. actinomycetemcomitans American Type Control Culture (ATCC) serotypes a (ATCC ${ }^{\circledR} 43717^{\mathrm{TM}}$ ), b (ATCC $\AA 43718^{\mathrm{TM}}$ ), and C (ATCC $\AA 43719^{\mathrm{TM}}$ ) were incubated separately in TSBV agar in anaerobiosis at $37^{\circ} \mathrm{C}$ for 48 hours.

After this culture was made, an isolated colony was selected. Then, it was transferred to a tube with 5 $\mathrm{mL}$ of liquid brain heart infusion (BHI) medium supplemented with $10 \%$ equine serum (Oxoid $₫$, Basingstoke, UK) with the help of a sowing handle. This broth was reincubated at a temperature of $37^{\circ} \mathrm{C}$ for 48 hours. The turbidity of the inoculum was then adjusted with liquid heart infusion medium to 0.5 on the McFarland scale with the help of an Oxoid turbidometer (Fisher Scientific Company ${ }^{\circledR}$, Ottawa, Canada) to obtain approximate suspensions of $1 \times 10^{8}$ UFC/mL. Individual suspensions of each serotype and a multispecies suspension were used for the study. After suspensions of the three serotypes were obtained, a multispecies suspension was performed by adding $5 \mathrm{~mL}$ of each inoculum to a tube, i.e., serotypes $\mathrm{a}, \mathrm{b}$, and c. The tubes were shaken in a Vortex Super Mixer stirrer (Lab-line Instruments, Inc. ®, Melrose Park, USA) to achieve homogeneity. Then, the modified direct contact test was performed according to the protocol described by Zhang et al. (2009).

With a scalpel handle and leaf number of 15 , each membrane was divided into three segments: head, body, and tail. To obtain these segments, each membrane was measured and divided into three equal zones. A 96-well microtiter plate (Sarstedt, Inc. $®$, Newton, NC) was maintained vertically, and a fixed-size area on the sidewall of the wells was covered with approximately a similar amount of each L-PRF segment, tacking them to the site with an anatomical clamp.

After the mix and L-PRF segments were properly placed, 1- and 24-hour intervals were tested.

To test the antibacterial activity of L-PRF and each specific segment, $10 \mu \mathrm{l}$ of the multispecies suspension was placed on each segment for each of the three groups (head, body, and tail). It was also done with $10 \mu \mathrm{l}$ of serotype a suspension, serotypes $b$, and $c$. In addition, positive and negative monitoring was carried out.

Six groups were held: positive control (multispecies inoculum plus antibiotic), negative control (serotypes a, b, c, and $\mathrm{m}$ plus water, without L-PRF), a (inoculum serotype a plus L-PRF), b (inoculum serotype b plus L-PRF), c (inoculum serotype c plus L-PRF), and m (multispecies inoculum plus L-PRF) (Fig. 3).

After incubation in $100 \%$ humidity at $37^{\circ} \mathrm{C}$ at time intervals of 1 and 24 hours, $215 \mu$ l of tryptic soy broth (TSB) (Oxoid, Basingstoke, UK) was added to each well. The initial inoculum in all groups was $4 x$ $10^{6} \mathrm{UFC} / \mathrm{mL}$. After mixing with a micropipette for 1 minute, the bacterial suspension of each well was transferred and diluted 4 times in series in TSBV. 
Time : 1 hour

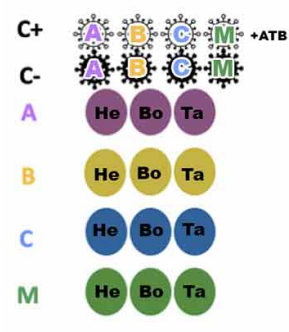

1

4 membranes

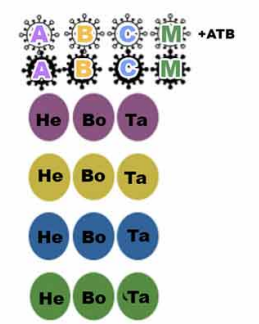

2

4 membranes

12 membranes

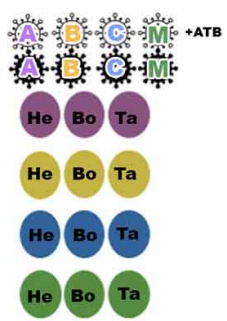

3

4 membranes

Time : 24 hours
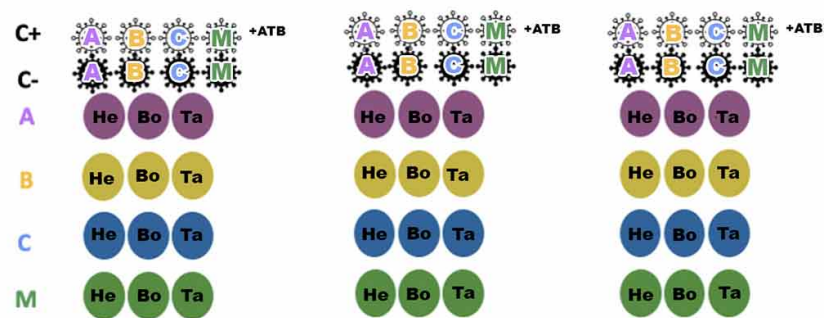

2

3

4 membranes

4 membranes

4 membranes

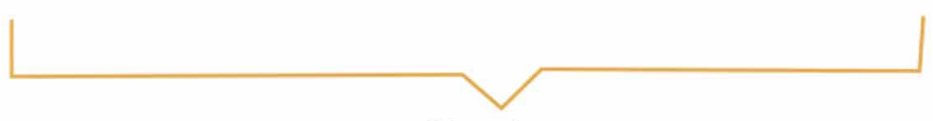

24 membranes

Fig. 3. Modified direct contact test groups.

To evaluate the survival kinetics of bacteria, petri plates with BHA heart brain agar (Oxoid $\AA$, Basingstoke, UK) were divided into five parts and plated in each segment, with approximately 3 to 4 drops corresponding to $20 \mu \mathrm{L}$ of the undiluted suspension and 4 serial dilutions. It was important that the agar plates were completely dry so that the droplets were absorbed almost instantly. The plates were then incubated at $37^{\circ} \mathrm{C}$ for 24 hours, and a colony count was then performed with colony counter equipment (BOECO ${ }^{\circledR}$, Hamburg, Germany).

Statistical analysis. The study was based on descriptive statistics by presenting central trends and dispersion measures. The data were flushed into an Excel spreadsheet based on logarithms. For analysis of data through tables and graphs, IBM SPSS 25 software was used.

\section{RESULTS}

The initial inoculum in all groups was 6,6 $\times 10^{6}$ UFC/mL. At the first time point ( 1 hour), Fig. 4 (a and c) shows that serotypes a and c decreased their bacterial concentration in all areas. Serotype b, Fig. 4 (b), also shows a decrease in its head and body zones but an increase in its tail zone. For serotype m (Fig. 4 (d)), decreased concentrations in the body and tail and an increase in the head were observed.
For timepoint 2 (24 hours), the concentration increased in all zones (head, body, and tail) for serotypes a, b, c, and $m$ relative to time 1 (Fig. 4). The difference between the unit-forming colonies at the initial inoculum (time 0) and time 1 was statistically significant (Table I).

Table I. Colony forming unit (in Log values) for times 0, 1 (1 hour), y 2 (24 hours).

\begin{tabular}{cccc}
\hline Time & Mean & Mean Rank & $\mathrm{p}$ (ANOVA) \\
\hline 0 & 6.60 & $0.54 \mathrm{~B}$ & \\
1 & 5.15 & $0.31 \mathrm{~A}$ & $=0.04$ \\
2 & 5.92 & $0.31 \mathrm{AB}$ & \\
\hline
\end{tabular}

\section{DISCUSSION}

This study sought to assess the potential for antimicrobial properties that could occur in the different zones of L-PRF. Through the modified direct contact test, the antimicrobial potential of L-PRF and its different zones was evaluated against different strains of $A$. actinomycetemcomitans serotypes a, b, c, and a multispecies serotype (with serotypes a, b, and c). This test was performed at two time intervals: 1 hour and 24 hours.

Several studies explored the antimicrobial effect of L-PRF, but few studies have analyzed the effect in detail and in relation to periodontal bacteria (Yang et al., 2015; Badade et al., 2016). In addition, it is difficult 


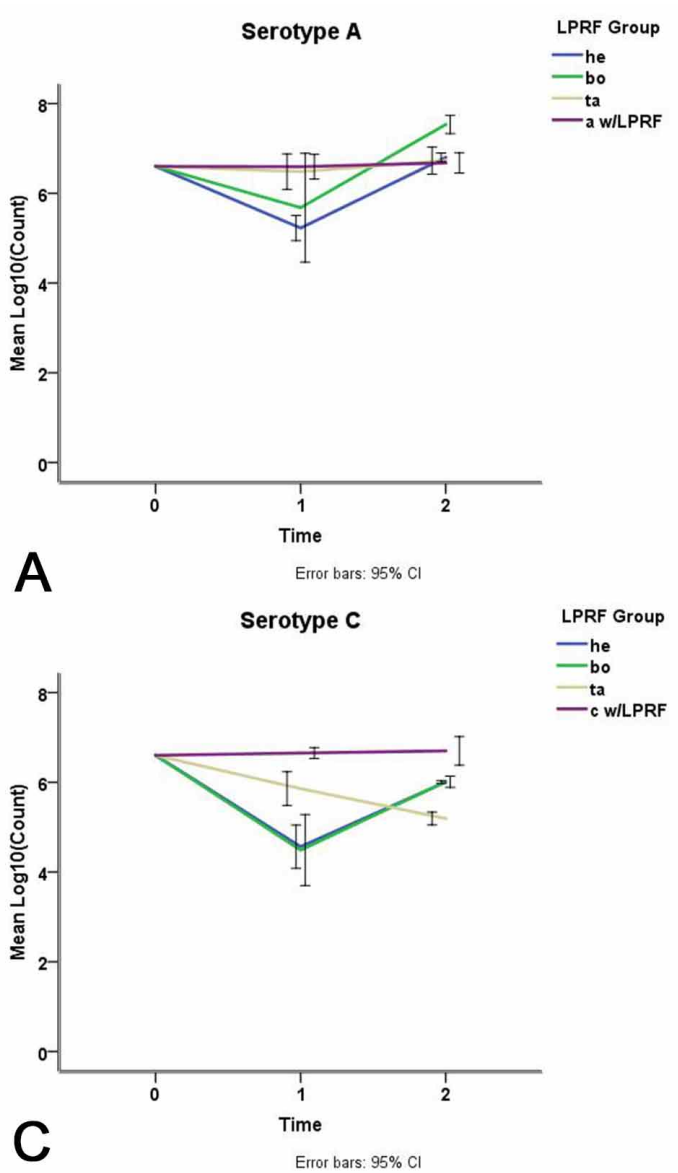

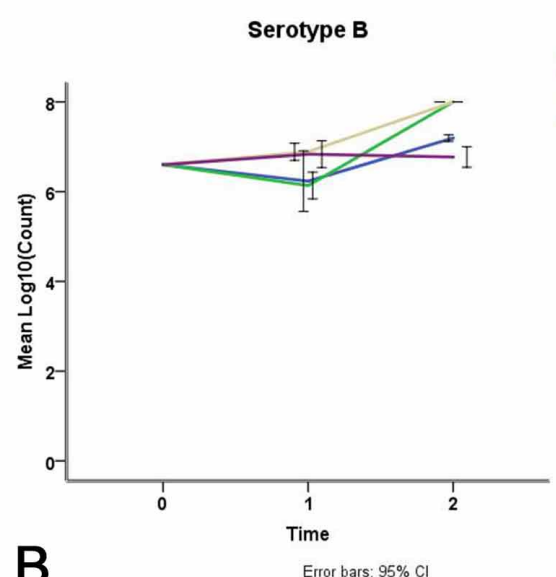

LPRF Group
$\begin{aligned} & \text { he } \\ & - \text { bo } \\ & \text { ta } \\ & -\mathrm{b} \text { wILPRF }\end{aligned}$

B

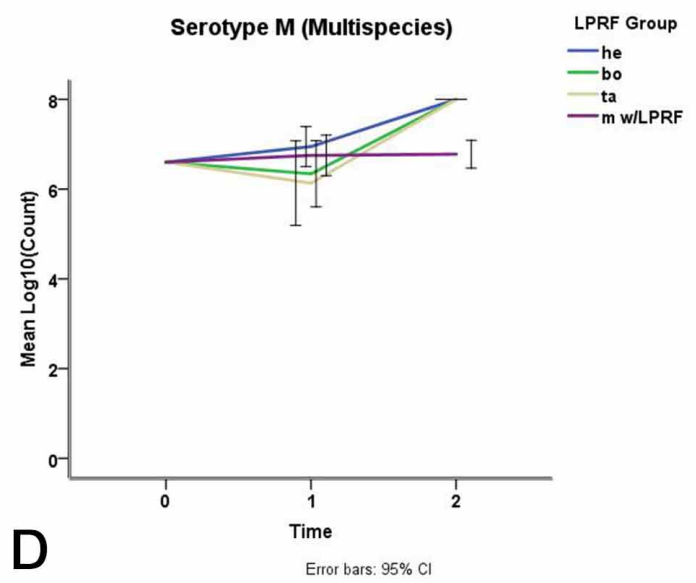

Fig. 4. Bacterial growth for different times: 0, 1 (1 hour), 2 (24 h) and zones: he (head), bo (body), ta (tail), with their respective negative control groups: a w/LPRF (serotype a without L-PRF), b w/LPRF(serotype b without L-PRF), c w/LPRF(serotype c without L-PRF), m/LPRF(serotype $m$ without L-PRF). (A) Serotype a, (B) serotype b, (C) serotype $c$, (D) serotype $m$.

to correlate the available studies due to the varied nomenclatures of platelet derivatives and the different protocols available for formulation.

At time 1, our results showed that the area with the most antimicrobial power was the head, followed by the body, and finally the tail. This could be explained by the cellular and fibrin configuration of each zone where the head is the zone with more cellular content decreasing to the tail (Dias et al.). This cellular content refers to platelets and leukocytes in their defense against the host (Róz'alski et al., 2013; Bielecki \& Dohan Ehrenfest, 2012b). Thus, in the area of the tail, more bacterial growth was found for serotypes $a, b$, and $c$. Reports of the antibacterial properties of the different areas of L-PRF against different serotypes of A. actinomycetemcomitans could not be found, suggesting that these are not yet fully understood. In the present study, the area of the head was the one that had the least growth in serotype a, with similar results in the body area in serotypes $b$ and $c$. On the other hand, a totally opposite result was given for serotype $\mathrm{m}$, where the head was the zone with the most growth, followed by the body, and then the tail.

Yang et al. (2005) demonstrated that PRP allowed inhibition of $P$. gingivalis and $A$. actinomycetemcomitans but not Fusobacterium nucleatum. One study found no antimicrobial L-PRF activity against $P$. gingivalis and $A$. actinomycetemcomitans when compared to PRP, which would not agree with the results obtained at time 1 . The authors suggested that the strongest bacterial inhibition of PRP when compared with L-PRF could be due to calcium chloride (Badade et al.). In some PRP techniques for activating platelets and inducing fibrin formation, thrombin or calcium chloride is added to the preparation 
LANATA-SELINGUE, N.; BETANCUR, D.; BELLO-TOLEDO, H.; GONZÁLEZ-ROCHA, G.; LUENGO, L. \& SÁNCHEZ-SANHUEZA, G. Antimicrobial effect of leukocyte- and platelet-rich fibrin against an Aggregatibacter actinomycetemcomitans mono-multiserotype model. Int. J. Odontostomat., 15(4):1035-1042, 2021.

(Arnoczky et al., 2013). Calcium Chloride could inhibit microbial growth (Lawrence et al., 2003). Another study, where bacterial plaque samples were taken from patients with gingivitis, showed opposite results; PRF demonstrated significant antimicrobial activity when compared to PRP, which would be similar to what was seen in our results at time 1 (Karde et al., 2017). The study authors did not speculate on the cause of this difference between PRP and PRF.

In the current study, at time 1, L-PRF had bacteriostatic power against some strains of $A$. actinomycetemcomitans. These results contrast with the findings of Castro et al. (2019) where researchers did not find an inhibition of this bacteria, and when in contact with L-PRF exudate, $A$. actinomycetemcomitans increased. It is important to note that Castro and colleagues performed their analysis in relation to a polymerase chain reaction and in L-PRF exudate, which differs from our analysis. In the Kour et al. (2018), study, the antimicrobial power of PRF and PRP against $A$. actinomycetemcomitans was evaluated. Both tested positive for antimicrobial properties, which was more pronounced when using PRP. The researchers attribute this difference to the fact that platelets and cytokines in PRF are found within the fibrin mesh and will be released when it disintegrates, for which a longer measurement time may be necessary.

The most aggressive serotype in this study was multispecies, which was a mixture of equal amounts of serotypes a, b, and c. In many patients with periodontitis, coinfection of two or three serotypes of $A$. actinomycetemcomitans are found (Rylev \& Kilian, 2008). In the Rojas et al. (2018) study, it was found that in coinfection by serotypes $a$ and $b$, serotype a works by decreasing the immunostimulation potential of $b$.

The serotype that, by itself, was the most aggressive in this study was $b$, followed by $a$ and then c. This is in accordance with the Rojas et al. (2020), study, where researchers evaluated the immunogenic potential of different serotypes, and $b$ was seen to have the greatest immune stimulator potential. Similarly, another study (Monasterio et al., 2018), which analyzed the potential to produce alveolar reabsorption, found that the most pathogenic serotype was b. In addition, the LPS of this serotype has been shown to be a more potent immunogen than other serotypes (Díaz-Zúñiga et al., 2015). Serotype b has been associated with periodontitis (Haubek et al., 2008), and some studies associate serotypes $b$ and $c$ with an increased risk of periodontitis in the future (Pietiäinen et al., 2018). Despite evidence from multiple studies, the correlation between serotypes and periodontal conditions remains confusing (Brígido et al., 2014).

For time 2 (24 hours) in the present study, an increase in the growth of all serotypes (a, b, c, and $\mathrm{m}$ ) and in all areas of the L-PRF (head, body, tail) was found (by comparison with the negative control). That is, L-PRF acted as a promoter of the growth of $A$. actinomycetemcomitans, which is consistent with Castro et al. findings, where they attribute this effect to human serum stimulating leucotoxic activity in this bacterium. This would also be aligned with the study of Tang-Siegel et al. (2016), which found that some strains of $A$. actinomycetemcomitans respond to human serum by showing rapid growth.

The study has several limitations. First, it was an in vitro experiment, and as such, it cannot exactly reproduce the complexity of the in vivo conditions (Lorian, 1989). Additionally, the patient sample was quite small, and the relationship of L-PRF was analyzed with only a single periodontal bacterium.

It would be interesting to conduct an ELISA study to search for antimicrobial peptides in L-PRF in order to relate an antimicrobial effect. To the best of our knowledge, this is the first study to analyze the microbiological potential of different areas of L-PRF.

\section{CONCLUSIONS}

For the first time, it can be noted that the areas with more cellular content, that is, regions of the head and body, are the ones with the most antimicrobial power. L-PRF would have better results with serotype c. At time 2, L-PRF is likely to act as a growth promoter of A. actinomycetemcomitans.

LANATA-SELINGUE, N.; BETANCUR, D.; BELLOTOLEDO, H.; GONZÁLEZ-ROCHA, G.; LUENGO, L. \& SÁNCHEZ-SANHUEZA, G. Efecto antimicrobiano de la fibrina rica en plaquetas y leucocitos contra Aggregatibacter actinomycetemcomitans en un modelo mono- multi serotipo. Int. J. Odontostomat., 15(4) :1035-1042, 2021.

RESUMEN: La Fibrina rica en Leucocitos y Plaquetas es un concentrado plaquetario ampliamente utilizado en procedimientos quirúrgicos periodontales. Muchos beneficios se describen con respecto a su uso, tales como propieda- 
des antimicrobianas. El objetivo de este estudio fue evaluar los efectos antimicrobianos de las diferentes zonas de este concentrado plaquetario frente a los serotipos más prevalentes de Aggregatibacter actinomycetemcomitans en un modelo mono-multi serotipo in vitro. Se incluyeron tres pacientes que fueron tratados en la Facultad de Odontología de la ciudad donde residen los investigadores. Se utilizó para su análisis una prueba de contacto directo modificado. En la prueba de contacto directo modificado, se encontró una disminución en el recuento bacteriano en el tiempo 1, pero en el tiempo 2, el recuento aumentó para todos los serotipos y zonas de L-PRF. Se puede observar que las áreas con mayor contenido celular en la Fibrina rica en Leucocitos y Plaquetas son las áreas con mayor poder antimicrobiano. Este concentrado de plaquetas tendría mejores resultados con el serotipo c. En el tiempo 2, es probable que actúe como un promotor del crecimiento de $A$. actinomycetemcomitans.

PALABRAS CLAVE: Aggregatibacter actinomycetemcomitans, implantes dentales, infecciones, fibrina rica en plaquetas.

\section{REFERENCES}

Aboltins, C.; Daffy, J.; Choong, P. \& Stanley, P. Current concepts in the management of prosthetic joint infection. Inter. Med. J., 44(9):834-40, 2014.

Anwandter, A.; Bohmann, S.; Nally, M.; Castro, A. B.; Quirynen, M. \& Pinto, N. Dimensional changes of the post extraction alveolar ridge, preserved with Leukocyte- and Platelet Rich Fibrin: A clinical pilot study. J. Dent., 52:23-9, 2016.

Arnoczky, S. P.; Sheibani-Rad, S. \& Shebani-Rad S. The basic science of platelet-rich plasma (PRP): what clinicians need to know. Sports Med Arthrosc., 21(4):180-5, 2013.

Badade, P. S.; Mahale, S. A.; Panjwani, A. A.; Vaidya, P. D. \& Warang, A. D. Antimicrobial effect of platelet-rich plasma and platelet-rich fibrin. Indian J. Dent. Res., 27(3):300-4, 2016.

Bielecki, T. \& Dohan Ehrenfest, D. M. Leukocyte- and Platelet-Rich Plasma (L-PRP)/Fibrin (L-PRF) in medicine: past, present, future. Curr. Pharm. Biotechnol., 13(7):i-ii, 2012.

Bielecki, T. \& Dohan Ehrenfest, D. M. Platelet-rich plasma (PRP) and Platelet-Rich Fibrin (PRF): surgical adjuvants, preparations for in situ regenerative medicine and tools for tissue engineering. Curr. Pharm. Biotechnol., 13(7):1121-30, 2012.

Bielecki, T.; Dohan Ehrenfest, D. M.; Everts, P. A. \& Wiczkowski, A. The role of leukocytes from L-PRP/L-PRF in wound healing and immune defense: new perspectives. Curr. Pharm. Biotechnol., 13(7):1153-62, 2012.

Bootkrajang, M.; Chinkrua, C. \& Aschaitrakool, Y. The effect of warfarin on the fibrin architecture of platelet-rich fibrin. $J$. Craniofac. Surg., 31(1):13-8, 2020.

Brígido, J. A.; da Silveira, V. R. S.; Rego, R. O. \& Nogueira, N. A. P. Serotypes of Aggregatibacter actinomycetemcomitans in relationto periodontal status and geographic origin of individualsa review of the literature. Med. Oral Patol. Oral Cir. Buca., 19(2):184, 2014.

Castro, A. B.; Herrero, E. R.; Slomka, V.; Pinto, N.; Teughels, W. \& Quirynen, M. Antimicrobial capacity of leucocyte-and platelet rich fibrin against periodontal pathogens. Sci. Rep., 9(1):8188, 2019.
Choukroun, J.; Diss, A.; Simonpieri, A.; Girard, M. O.; Schoeffler, C.; Dohan, S. L.; Dohan, A. J. J.; Mouhyi, J. \& Dohan, D. M. Plateletrich fibrin (PRF): A second-generation platelet concentrate. Part IV: Clinical effects on tissue healing. Oral Surg. Oral Med. Oral Pathol. Oral Radiol. Endod., 101(3):56-60, 2006.

De Bruyn, H.; Bouvry, P.; Collaert, B.; De Clercq, C.; Persson, G. R. \& Cosyn, J. Long-term clinical, microbiological, and radiographic outcomes of Brånemarktm implants installed in augmented maxillary bone for fixed full-arch rehabilitation. Clin. Implant. Dent. Relat. Res., 15(1):73-82, 2013.

Dias, F. J.; Venegas, C.; Borie, E.; Arias, A.; Watanabe, I. \& Fuentes, R. A new insight of platelet-rich fibrin clots morphology and their elemental composition. Tissue Cell., 65:101362, 2020.

Díaz-Zúñiga, J.; Melgar-Rodríguez, S.; Alvarez, C.; Monasterio, G.; Benítez, A.; Ciuchi, P.; Díaz, C.; Mardones, J.; Escobar, A.; Sanz, M.; et al. T-lymphocyte phenotype and function triggered by Aggregatibacter actinomycetemcomitans is serotypedependent. J. Periodontal Res., 50(6):824-35, 2015.

Dohan Ehrenfest, D. M. How to optimize the preparation of leukocyte- and platelet-rich fibrin (L-PRF, Choukroun's technique) clots and membranes: introducing the PRF Box. Oral Surg. Oral Med. Oral Pathol. Oral Radiol. Endod., 110(3):275-8, 2010.

Dohan Ehrenfest, D. M.; Choukroun, J.; Diss, A.; Dohan, S. L.; Dohan, A. J. J.; Mouhyi, J. \& Gogly, B. Platelet-rich fibrin (PRF): a second-generation platelet concentrate. Part I: technological concepts and evolution. Oral Surg. Oral Med. Oral Pathol. Oral Radiol. Endod., 101(3):37-44, 2006.

Dohan Ehrenfest, D. M.; Pinto, N. R.; Pereda, A.; Jiménez, P.; Del Corso, M.; Kang, B. S.; Nally, M.; Lanata, N.; Wang, H. L. \& Quirynen, M. The impact of the centrifuge characteristics and centrifugation protocols on the cells, growth factors, and fibrin architecture of a leukocyte- and platelet-rich fibrin (L-PRF) clot and membrane. Platelets, 29(2):171-184, 2018.

Dohan Ehrenfest, D. M.; Rasmusson, L. \& Albrektsson, T. Classification of platelet concentrates: from pure platelet-rich plasma (P-PRP) to leucocyte- and platelet-rich fibrin (L-PRF). Trends Biotechnol., 27(3):158-67, 2009.

Flores, R. R. Aggregatibacter actinomycetemcomitans. Rev. Chil. Infectol., 28(6):579-80, 2011.

Haubek, D.; Ennibi, O. K.; Poulsen, K.; Væth, M.; Poulsen, S. \& Kilian, M. Risk of aggressive periodontitis in adolescent carriers of the JP2 clone of Aggregatibacter (Actinobacillus) actinomycetemcomitans in Morocco: a prospective longitudinal cohort study. Lancet, 371(9608):237-42, 2008.

Herbert, B. A.; Novince, C. M. \& Kirkwood, K. L. Aggregatibacter actinomycetemcomitans, a potent immunoregulator of the periodontal host defense system and alveolar bone homeostasis. Mol. Oral Microbiol., 31(3):207-27, 2016.

Karde, P.; Sethi, K.; Mahale, S.; Khedkar, S.; Patil, A. \& Joshi, C. Comparative evaluation of platelet count and antimicrobial efficacy of injectable platelet-rich fibrin with other platelet concentrates: An in vitro study. J. Indian Soc. Periodontol., 21(2):97, 2017.

Khiste, S. V. \& Naik Tari, R. Platelet-rich fibrin as a biofuel for tissue regeneration. ISRN Biomaterials, 1-6, 2013.

Kobayashi, M.; Kawase, T.; Horimizu, M.; Okuda, K.; Wolff, L. F. \& Yoshie, H. A proposed protocol for the standardized preparation of PRF membranes for clinical use. Biologicals, 40(5):323-9, 2012.

Kour, P.; Pudakalkatti, P.; Vas, A.; Das, S. \& Padmanabhan, S. Comparative evaluation of antimicrobial efficacy of platelet-rich plasma, platelet-rich fibrin, and injectable platelet-rich fibrin on the standard strains of Porphyromonas gingivalis and Aggregatibacter actinomycetemcomitans. Contemp. Clin. Dent., 9(6):325, 2018. 
LANATA-SELINGUE, N.; BETANCUR, D.; BELLO-TOLEDO, H.; GONZÁLEZ-ROCHA, G.; LUENGO, L. \& SÁNCHEZ-SANHUEZA, G. Antimicrobial effect of leukocyte- and platelet-rich fibrin against an Aggregatibacter actinomycetemcomitans mono-multiserotype model. Int. J. Odontostomat., 15(4):1035-1042, 2021.

Kumar, R. V. \& Shubhashini, N. Platelet rich fibrin?: a new paradigm in periodontal regeneration. Cell Tissue Bank, 14(3):453-63, 2013.

Lawrence, T.; Dikeman, M.; Hunt, M.; Kastner, C. \& Johnson, D. Effects of calcium salts on beef longissimus quality. Meat Sci., 64(3):299-308, 2003

Lorian, V. In vitro simulation of in vivo conditions: physical state of the culture medium. J. Clin. Microbiol., 27(11):2403-6, 1989.

Monasterio, G.; Castillo, F.; Ibarra, J. P.; Guevara, J.; Rojas, L.; Alvarez, C.; et al. Alveolar bone resorption and Th1/Th17associated immune response triggered during Aggregatibacter actinomycetemcomitans -induced experimental periodontitis are serotype-dependent. J. Periodontol., 89(10):1249-61, 2018.

Moojen, D. J. F.; Everts, P. A. M.; Schure, R. M.; Overdevest, E. P.; van Zundert, A.; Knape, J. T. A.; Castelein, R. M.; Creemers, L. B.; Wouter, J. A. \& Dhert, J. A. Antimicrobial activity of plateletleukocyte gel against Staphylococcus aureus. J. Orthop. Res., 26(3):404-10, 2008.

Nelson, S. \& Thomas, G. Bacterial persistence in dentoalveolar bone following extraction?: a microbiological study and implications for dental implant treatment. Clin. Implant. Dent. Relat. Des., 12(4):306-14, 2010.

Newman, M. G.; Socransky, S. S.; Savitt, E. D.; Propas, D. A. \& Crawford, A. Studies of the microbiology of periodontosis. J. Periodontol., 47(7):373-9, 1976.

Pietiäinen, M.; Kopra, K. A. E.; Vuorenkoski, J.; Salminen, A.; Paju, S.; Mäntylä, P.; Buhlin, K.; Liljestrand, J. M.; Nieminen, M. S.; Sinisalo, J.; et al. Aggregatibacter actinomycetemcomitans serotypes associate with periodontal and coronary artery disease status. J. Clin. Periodontol., 45(4):413-21, 2018.

Quirynen, M.; De Soete, M. \& van Steenberghe, D. Infectious risks for oral implants: a review of the literature. Clin. Oral Implants Res., 13(1):1-19, 2002.

Raja, M.; Ummer, F. \& Dhivakar, C. P. Aggregatibacter actinomycetemcomitans - a tooth killer? J. Clin. Diagn. Res., 8(8):13-6, 2014

Rojas, L.; Melgar-Rodríguez, S.; Díaz-Zúñiga, J.; Alvarez, C.; Monasterio, G.; Rojas, C.; Carvajal, P. \& Vernal, R. Serotype a of Aggregatibacter actinomycetemcomitans down-regulates the increased serotype b-induced cytokine and chemokine production in dendritic cells. Arch. Oral Biol., 93:155-62, 2018.

Rojas, L.; Melgar-Rodríguez, S.; Díaz-Zúñiga, J.; Alvarez, C.; Monasterio, G.; Rojas, C.; Cafferata, E. A.; Hernández, M.; Cortéz, C.; Carvajal, P.; et al. Inhibitory effect of serotype a of Aggregatibacter actinomycetemcomitans on the increased destructive potential of serotype b. Oral Dis., 26(2):409-18, 2020.

Rózalski, M. I.; Micota, B.; Sadowska, B.; Paszkiewicz, M.; Wie ckowska-Szakiel, M. \& Róz'alska, B. Antimicrobial/antibiofilm activity of expired blood platelets and their released products. Postepy Hig. Med. Dosw., 67:321-5, 2013.

Rylev, M. \& Kilian, M. Prevalence and distribution of principal periodontal pathogens worldwide. J. Clin. Periodontol., 35:34661,2008

Slots, J. \& Ting, M. Actinobacillus actinomycetemcomitans and Porphyromonas gingivalis in human periodontal disease: occurrence and treatment. Periodontol. 2000, 20:82-121, 1999.

Tang-Siegel, G.; Bumgarner, R.; Ruiz, T.; Kittichotirat, W.; Chen, W. \& Chen, C. Human serum-specific activation of alternative sigma factors, the stress responders in Aggregatibacter actinomycetemcomitans. PLoS One, 11(8):e0160018, 2016.

Yang, H. W.; Huang, Y. F.; Chan, Y. \& Chou, M. Y. Relationship of Actinobacillus actinomycetemcomitans serotypes to periodontal condition: prevalence and proportions in subgingival plaque. Eur. J. Oral Sci., 113(1):28-33, 2005.
Yang, L. C.; Hu, S. W.; Yan, M.; Yang, J. J.; Tsou, S. H. \& Lin, Y. Y. Antimicrobial activity of platelet-rich plasma and other plasma preparations against periodontal pathogens. J. Periodontol., 86(2):310-8, 2015.

Zhang, H.; Shen, Y.; Ruse, N. D. \& Haapasalo, M. Antibacterial activity of endodontic sealers by modified direct contact test against Enterococcus faecalis. J. Endod., 35(7):1051-5, 2009.

Corresponding author:

Gabriela Sánchez-Sanhueza

Roosevelt 1550

Universidad de Concepción-Box 160-C

Concepción

CHILE

E-mail: gasanchez@udec.cl 